\title{
Textiles \& Apparel as UV Protectives in Medical Applications
}

\author{
Ahmed Ali Salman ${ }^{1}$, Z. M. Abdel-Megied ${ }^{2}$, Dr. Nahla .Abd El-Mohsen .H .A ${ }^{3}$, Seddik K. M. ${ }^{4}$, \\ Manar .Y .Abd El-Aziz ${ }^{5}$ \\ ${ }^{1}$ Helwan University, Faculty of Applied Arts, Dokki, Giza, Egypt \\ ${ }^{2}$ National Research Centre, Textile Research Division, Dokki, Giza, Egypt \\ ${ }^{3}$ Helwan University, Faculty of Applied Arts, Dokki, Giza, Egypt \\ ${ }^{4}$ National Research Centre, Textile Research Division, Dokki, Giza, Egypt \\ ${ }^{5}$ National Research Centre, Textile Research Division, Dokki, Giza, Egypt
}

\begin{abstract}
Ultraviolet radiations influence humans' life. These radiations can cause a range of effects from simple tanning to highly malignant skin cancers if unprotected and it affects the humans' eye. Clothing fabrics' construction can help to increase protection from radiations, by choosing suitable construction parameters. Also treatment can improve UV protection of fabrics. This article was written to update information on $U V$ radiations, $U V$ effects on humans' health and fabrics' parameters which help to protect from $U V$ radiation.
\end{abstract}

Keywords: Protective fabrics, UV radiation, Fabric construction, Health effects, UPF, SPF

\section{Introduction}

Virtually all energy required to sustain life comes from the sun; without the sun, life as we know it would be impossible [1]. Humans have always lived their lives according to the sun. Yet, no matter how vital the sun is for life on earth, it also carries risks of toxicity. Although the fact that the sun is harmful to the skin has been known from many years, raising awareness of sun protection methods is a long and difficult process [2].

In medical field it is very important for patient who have skin sensibility must take care to wear clothes with high protection from ultraviolet radiations to protect their skin also for the jaundiced Childs' eye which must be protected with eye patch with high UPF and also some other patient who make a specially therapy using UV-A or UV-B radiations, All of those must be well protected.

\section{Definition of UV Radiations}

Ultraviolet radiation is a sun radiant energy coming from the sun emits, arrange of energy known as electromagnetic spectrum [3], which can be described by two major theories, the wave and the quantum or corpuscular theory. There is a relation between the radiations' wavelength, frequency and its velocity, but the absorption and the emission of light cannot be fully explained by the wave theory. The basic elements of the quantum theory of light are energetic packets known as photons. According to this theory, higher frequency light has a higher energy and a shorter wavelength. Ultraviolet radiation is a light with high energy and short wavelength [4], [5]. Sunlight is a form of electromagnetic radiation in the form of ultraviolet (UV), visible, and infrared radiation [1]. with spectrum extends from $290 \mathrm{~nm}$ to $3000 \mathrm{~nm}$. Ultraviolet radiations is just about
$7 \%$ of total solar emission with spectrum extends from 290 $\mathrm{nm}$ to $400 \mathrm{~nm}$ but it has a huge dangerous effects on human skin. When the ozone layer is thinned, these effects may cause serious health problems [1], [4]. Such acute effects include sun tanning and erythema (sunburn). Chronic overexposure can lead to connective-tissue damage (photo aging'), premalignant lesions (e.g. actinic keratosis) and malignancies (basal - or squamous - cell cancer, and perhaps melanoma skin cancer) [1].

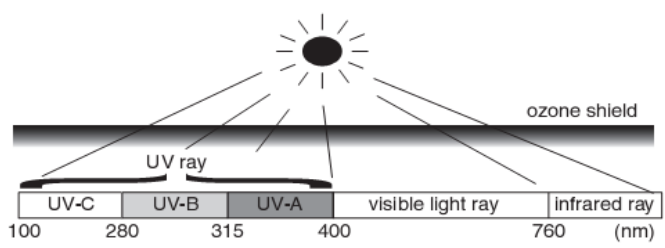

Figure 1: UV radiation spectrum [6]

\section{Categories of Ultraviolet Radiations}

- UV-A (320-400 nm): UV-A rays are the least powerful of the UV rays, but it can penetrate deeply in to the skin and contribute to premature aging of the skin and skin cancers [3]. However, it takes roughly 1,000 times the doses of UVA to produce sunburn and tanning effects equivalent to those of UVB [1].

- UV-B (280-320 $\mathbf{n m})$ : UV-B rays are the most powerful and potentially harmful form of radiation. It is the most common cause of sunburn, aging, wrinkling and skin cancer. UV-B is particularly strong at the equator, at high elevations or during the summer.

- UV-C (200-280 $\mathbf{n m})$ : UV-C rays are the shortest and the most powerful of the UV rays, UV-C is the most likely to cause cancer if it reaches skin. Fortunately, most of it is absorbed by the ozone layer in our atmosphere $[3,7$, and $8]$. 


\section{International Journal of Science and Research (IJSR) \\ ISSN (Online): 2319-7064}

Index Copernicus Value (2013): 6.14 | Impact Factor (2014): 5.611

- So the order of potency has been decided as UVC $>$ UVB $>$ UVA [9].

\section{Definition of Sun Protective Clothing, SPF and UPF}

It's clothing which has the ability to protect the skin from incident solar radiation because the fabric from which it is made can reflect, absorb and scatter solar wave lengths. Fabrics differ in their ability to attenuate light in this way because they differ in fiber composition and moisture content, as well as in type and concentration of dye, optical whiteners, or UV-absorbing finishes adsorbed to fibers [1].The definition of a sun protective fabric is a fabric that must achieve a minimum UV Protection Factor (UPF) rating of at least UPF15 after the equivalent of 2 years of normal wear and tear. UPF is similar to SPF (sun protection factor) used to rate sunscreens but UPF is the rating used to measure the amount of UV rays that pass through fabrics when exposed to UV radiation [10]. The Ultraviolet Protection Factor (UPF) of a fabric is a quantitative measurement of the effectiveness of the fabric to protect the human skin against ultraviolet radiation [11]. UPF ratings are shown in the table below:

Table 1: UPF ratings [12]

\begin{tabular}{|c|c|c|}
\hline UPF rating & $\%$ UV radiation absorbed & Protection category \\
\hline 10 & 90.0 & moderate \\
\hline 15 & 93.3 & good \\
\hline 20 & 95.0 & good \\
\hline 30 & 96.7 & very good \\
\hline 40 & 97.5 & excellent \\
\hline 50 & 98.0 & excellent \\
\hline
\end{tabular}

Each fabric must be tested to determine its ability to protect from solar radiation, as this cannot be known from visual observation nor calculated from descriptions of the fabric's composition and structure [1].

\section{Test Methods for Quantitative Assessment of UV Protection of Textiles}

\subsection{In Vitro}

Direct and diffuse UV transmittance through a fabric is the crucial factor determining the UV protection of textiles. Radiometric UV transmission tests use a broadband UV light source filtered for UV-B or combined UV-A and UV-B spectral regions to illuminate a fabric sample. The total UV transmission through the textile is measured by a radiometer. For correct measurement, this test method requires a UV source that closely matches the solar spectrum, with detectors that respond similarly to human skin. Nevertheless, this technique is simple and suitable when a relative variation in UPF needs to be measured. Spectroradiometers or spectrophotometers collect transmitted and scattered radiation with the aid of an integrating sphere positioned behind a textile sample.

Although spectrophotometers fitted with a double monochromator have a large dynamic range and high accuracy, regular scans of the UV source (deuterium or xenon arc lamp) are required to provide reference data. As suggested by the AS/NZS6 and European standard, the spectrophotometer should be fitted with a UV radiation transmitting filter for wavelengths of less than $400 \mathrm{~nm}$ (UG11 filter; Schott, Mainz, Germany) to minimize errors caused by fluorescence from whitening agents. The spectrophotometric measurements are performed in the wavelength range of 290 to $400 \mathrm{~nm}$, in 5-nm steps or less. For UPF determination, at least 4 textile samples must be taken from a garment, 2 in the machine direction and 2 in the cross-machine direction. To determine the in vitro UPF, the spectral irradiance (of the source and transmitted spectrum) is weighted against the erythemal action spectrum, as follows:

$$
\mathrm{UPF}=\int E_{\lambda} S_{\lambda} d_{\lambda} / \int E_{\lambda} S_{\lambda} T_{\lambda} d_{\nu_{0}},
$$

Where $\lambda$ is the wavelength in $\mathrm{nm}$; spectral effectiveness; 1 , solar spectral irradiance of the source in watts per square meter; ${ }^{-1}$, bandwidth in nanometer; and $T$, spectral transmission of the sample. The integrals are calculated over the wavelength range of 290 to $400 \mathrm{~nm}$. Analogous to the sun protection factor of sunscreens, UPF is defined as the ratio of the average effective UV irradiance calculated for unprotected skin to the average effective UV irradiance calculated for skin protected by the test fabric. Inter comparison measurements of different testing laboratories have shown that spectrophotometry is an accurate and reproducible test method for determining UPF, particularly for samples with UPFs below 50.8, However, UPFs of 50 and higher are only of theoretical interest, as even in Australia the maximum daily UV exposure is about 35 minimal erythema doses (MEDs). Ultraviolet transmission measurements of textiles are generally made under worst-case conditions, with collimated radiation at right angles to the fabric.

Thus, the actual UV protection of a particular textile would always be greater than the measurement obtained using spectrophotometry [13], [14].

\subsection{In Vivo}

With human volunteers, use of the sun as the UV source is impracticable to test the UPF of fabrics. Generally, xenon arc solar simulators are used, with filters to absorb wavelengths below $290 \mathrm{~nm}$ and to reduce visible and infrared radiation. Stanford and Gies and their coworkers described in vivo test methods based on MED testing.

However, the most frequently performed in vivo test method is in vivo confirmation of the UPFs measured in vitro. Based on skin photo type, MED is determined using incremental UV-B doses on the upper back of a subject and is read after 24 hours. To measure the MED of protected skin, a textile is placed over the skin on the other side of the back. The incremental UVB doses for determining the MED of 


\section{International Journal of Science and Research (IJSR) \\ ISSN (Online): 2319-7064 \\ Index Copernicus Value (2013): 6.14 | Impact Factor (2014): 5.611}

unprotected skin are multiplied by the UPF determined in vitro, with the product being the incremental UV-B doses for MED testing of the protected skin. The in vivo and in vitro methods are in agreement if the ratio of the MED of protected skin to the MED of unprotected skin results in the original in vitro UPF. Several studies, however, have shown that UPFs determined using the in vivo -n skin" method is significantly lower than the UPFs obtained in vitro. Again, as with the in vitro test method, the actual UPF of a garment would probably be much higher than the UPF determined using the in vivo test method. Cost and impracticability are limitations of the in vivo test methods. Some in vivo tests have used polysulfone dosimeters as small portable badges monitoring UV doses on mobile subjects. Ravishankar and Diffey concluded that the actual protection provided by textiles worn in sunlight is, on average, $50 \%$ higher than that measured by conventional in vitro testing using collimated radiation beams [3], [13].

\section{Standard test Methods}

Currently there are standard test methods for Australia/New Zealand(AS/NZS 4399), the USA (AATCC TM 183) and Great Britain (BS7914), respectively. All of these describe the procedures for determining the transmittance of UV radiation through fabric and describe how the UPF of the fabric tested is to be calculated [1].

\section{Health Effects of Exposure to UV Radiation}

The sunlight is important for life and people health, as the body use it to form vitamin-D, also human need it to enhance circulation of blood, invigorate the metabolism and improve resistance to many pathogens. But ultraviolet rays contained in sun light pose many risks and stress for the humans' skin [3].And also it has dangerous effects on humans' eye.

\subsection{Health Effects on Humans' Skin}

\subsubsection{The skin}

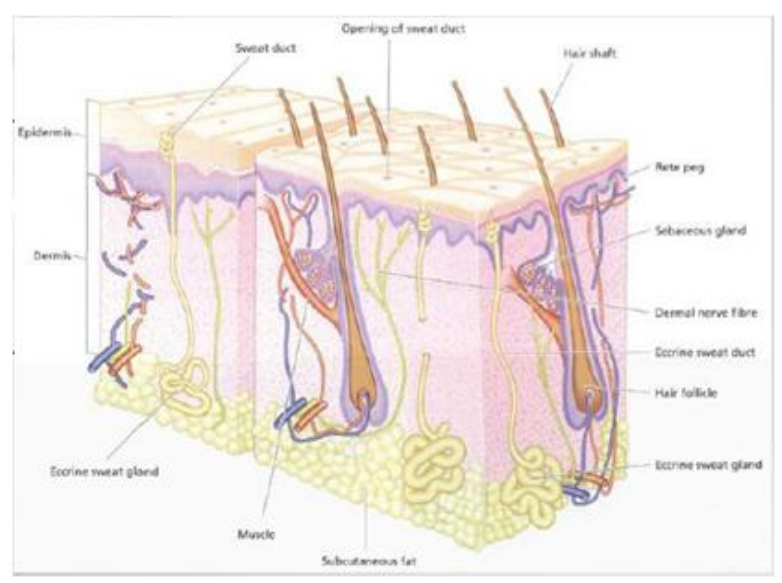

Figure 2: Human skin layers [19]

\subsubsection{Skin Types}

When human skin is exposed to UV it is absorbed, reflected, and scattered. Thus, the actual exposure received by the various layers of the skin will be lower than the incident exposure. For simplicity, skin sensitivity to UV can be divided into three general groups:

(a) Lightly pigmented: UV exposure causes sunburn but little tanning (e.g. Celtic populations). Characteristics of this group include fair or red hair, blue eyes and freckles. People in this group must take extra care in the sun as their skin is poorly protected and easily damaged.

(b) Intermediately pigmented: UV exposure results in little sunburn but tanning always occurs (e.g. southern Mediterranean and Asian populations). Characteristics of this group include darker hair and eyes. Although able to tan, people in this group can still burn and sustain significant skin damage from UV.

(c) Heavily pigmented: UV exposure rarely causes sunburn (e.g. Aboriginal, African and American Negroid populations). These populations have very good natural protection and are at little risk of skin cancer, but are, like all groups, subject to UV-induced eye damage and possibly reduced ability to combat infections when exposed to excessive UV levels.[15]

Table 2: Skin types [16]

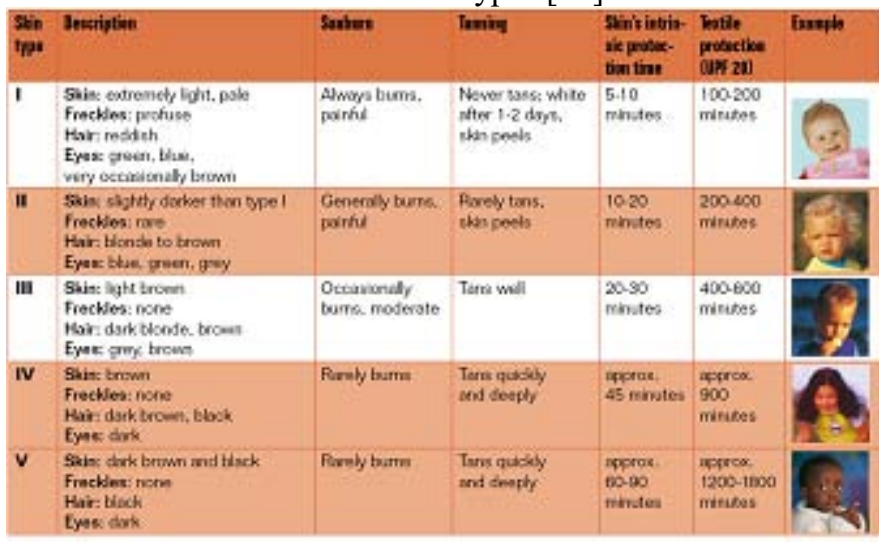

\subsubsection{Health Effects on The Skin}

The skin protects against UV exposure by increasing the amount of pigment (to produce skin darkening) and by increasing cell proliferation to produce thickening of the outer layer (stratum corneum). Health risks associated with exposure to UV include both acute and chronic effects and will vary according to the nature of the exposure. Factors important in assessing such risks include: the levels of UV impinging on the person exposed; the duration and frequency of occurrence of exposures; and the individual sensitivity of the person to UV as determined by their skin characteristics (see skin groups 1-3 above), genetic and other factors.

\section{(a) Short-term Effects}

\section{(1) Sunburn}

In its mildest form, sunburn consists of a reddening of the skin (erythema) that appears a few hours after UV exposure and reaches a maximum intensity between 8 and 24 hours, then fades over a few days [15].

\section{(2) Tanning}

When skin is exposed to UV, two distinct types of tanning reactions ensue. Firstly, immediate pigment darkening occurs, where melanin already in the skin darkens on

\section{Volume 4 Issue 12, December 2015}




\section{International Journal of Science and Research (IJSR) \\ ISSN (Online): 2319-7064}

Index Copernicus Value (2013): 6.14 | Impact Factor (2014): 5.611

exposure to UV and begins to fade within a few hours after cessation of exposure. Delayed tanning then occurs over about 3 days and can persist for several weeks. Exposure to UVB also results in an increase in the thickness of the epidermis. Because UVA does not produce thickening of the epidermis, the tan obtained from UV sun beds, while perhaps cosmetically acceptable in the short term, is less effective in protecting against further exposure to solar UV [8], [15].

\section{Photosensitivity}

A small percentage of people have a skin condition that makes them particularly sensitive to the sun's UV rays; this is called photosensitivity. Photosensitivity disease (porphyria) and photo-aggravated disease (e.g. lupus erythematosus) are triggered by minimal UV exposures. In addition, some medications, foods and cosmetics contain ingredients that may cause photosensitivity. This combination of chemicals or drugs with UV causes an adverse effect in the skin such as a rash or exaggerated sunburn.

\section{(b) Long-term Effects}

\section{(1) Effects Other Than Cancer}

The most common long term effects of UV exposure on the skin are:

- Dryness: As the outer layers thicken to protect it from the sun, the skin loses moisture.

- Blemishes: Blotchy discoloration from breakage of small blood vessels can be an early sign of sun damage.

- Aging: UV damages the elastin and collagen fibers in the lower layers of the skin causing loss of the skin's natural elasticity (wrinkles), mainly from UVA exposure. Excessive wrinkling from sun exposure gives the appearance of skin aging.

Freckles and solar brown spots (lentigines) are flat pigmented areas (usually no larger than $0.5 \mathrm{~cm}$ ) normally occurring on the sun-exposed skin of lightly pigmented people (e.g. Caucasians). Their prevalence is higher in those with highly sun-sensitive (group 1) skin. Freckles occur most commonly in children, while the frequency of solar lentigines increases with age and is greatest in those over 60 years of age (estimated at $75 \%$ in the USA).

Melanocytic naevi (moles) are benign growths of pigmented skin cells, usually beginning in the lower layer of the epidermis and later extending into the dermis. They are common in lightly pigmented or white populations and rare in black and Asian populations. In white populations they occur mainly on body sites that are maximally or intermittently exposed to the sun and are associated with an increased risk of melanoma.

Solar keratosis is a pre-cancerous growth of skin cells. Keratoses are very common on exposed body sites in lightly pigmented, older people living in areas of high levels of sunlight. Their number on the skin is strongly associated with the risk of non-melanocytic skin cancer [15].

\section{(2) Skin Cancer}

Skin cancer is the most common human cancer. About $95 \%$ of these are basal and squamous cell carcinomas (commonly referred to as "non-melanoma skin cancers"), the remaining $5 \%$ are malignant melanoma. The scientific evidence that sunlight is an important factor in the cause of skin cancers is convincing. While it is not unusual to have some moles or freckles, it is important to watch for any moles that change color, become bigger, itchy or inflamed, or that weep or bleed. These may be symptoms of melanoma or other skin cancers [15], [17].

\section{a) Non-melanoma Skin Cancer (NMSC)}

NMSCs are not usually fatal but can be very disfiguring if left untreated [18]. A number of facts have emerged from investigations of NMSCs:

- The most common NMSCs are squamous and basal cell carcinomas. About $75 \%$ of basal cell carcinomas and more than one-half of all squamous cell carcinomas occur on the head and neck, which are the sites of highest sun exposure. They also occur on the forearms and hands, or on any part of the body commonly exposed to the sun.

- Lightly pigmented people (group 1 skin) are much more likely to develop NMSC than those with higher pigmentation.

- An increased risk of non-melanoma skin cancer has been observed in relation to both freckling and the prevalence of solar lentigines (brown spots) in childhood.

- Hereditary factors associated with a tendency to develop skin cancer are light-colored eyes, fair complexion, light hair color, tendency to sunburn and poor ability to tan.

- Surveys of the incidence of skin cancer conducted in various countries yield ample evidence that the risk increases for people living closer to the equator. As a rough guide, the incidence doubles for every 100 decrease in latitude (about every $1000 \mathrm{~km}$ from the equator) provided that the population has the same hereditary factors.

- Studies have shown that people over 50 years of age who have worked outdoors for most of their lives are more likely to develop skin cancer than those working indoors.

\section{b) Melanoma}

Malignant melanoma is the least common but most dangerous type of skin cancer, with about $25 \%$ of diagnosed melanomas resulting in death. The number of cases of melanoma is rising at an alarming rate worldwide and at a much higher rate than other skin cancers. Studies have shown:

- While NMSCs occur predominantly on body sites of highest sun exposure (head, neck and hands), melanoma incidence on these sites is similar to that on partially sun exposed sites, such as the lower legs (women) and the back (men). Thus UV exposure is thought to be only one of the factors that increase a person's risk of developing melanoma.

- Melanoma is much more common in lightly pigmented people than in heavily pigmented people despite the fact that the latter tend to live in sunnier climates. However, hereditary factors such as the number of naevi or moles are more associated with melanoma than pigmentation. An increased risk of melanoma has been observed in relation to freckling in childhood.

\section{Volume 4 Issue 12, December 2015}




\section{International Journal of Science and Research (IJSR) \\ ISSN (Online): 2319-7064}

Index Copernicus Value (2013): 6.14 | Impact Factor (2014): 5.611

- A tendency to sunburn is a risk factor in developing melanoma, as is a history of infrequent, intense exposure resulting painful, blistering sunburn, particularly during childhood.

- In general, there is an inverse relationship between melanoma incidence and latitude of residence, although there are some inconsistencies. For example, in Europe the incidence is higher in Scandinavia than in Mediterranean countries. This apparent paradox may be explained by the obvious differences in skin sensitivity and by strong exposures to the sun during vacations in sunnier places.

- People who are born in Europe and migrate to sunnier countries after childhood have a risk of developing melanoma of about one-quarter that of people of European descent born in those countries. However, arrival during childhood results in a comparable risk [15].

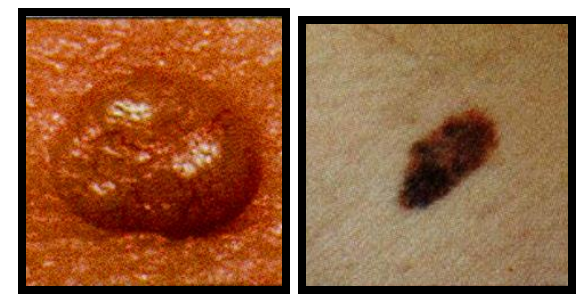

(a) Basal Cell (b) Malignant Melanoma Carcenoma Treatable Stage

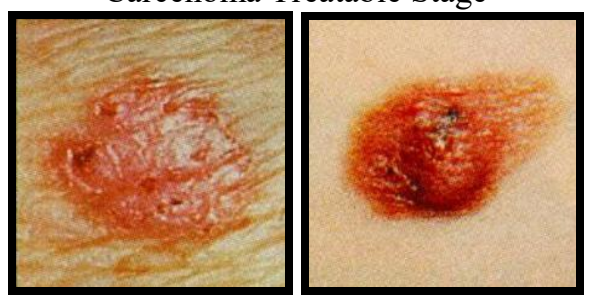

(c) Squamous Cell (d) Advanced stage Carcinoma Malignant Mellanoma

Figure 3: Skin Cancer Images [19]

\subsubsection{Skin Damage Wavelengths}

Commercial UVC penetrates the surface of the epidermis, UVB penetrates the epidermis, and UVA penetrates through the dermis just above the hypodermis,

Natural UVC rarely reaches the skin.

\section{(a) Biological Effects of UV-A Exposure to Skin}

- Suntans are related to UVA exposure. They do not cause sunburns because of their lower energy than UVB or UVC.

- Commercial UVA in the form of a black light emits long wave radiation with very little visible light.

- The long waves of UVA generate free radicals and causes indirect DNA damage which is responsible for malignant melanoma.

- Since UVA penetrate deeper they damage collagen fibers and destroy vitamin A.

\section{(b) Biological Effects of UV-B Exposure to Skin}

- Erythema or -sunburns"are related to UVB exposure. Symptoms depend on the intensity and or length of the exposure.

- Skin cancer, the most deadly form malignant melanoma, is caused by indirect DNA damage from UVB.

- $\quad$ Direct photochemical damage to DNA also causes skin cancers.

- One positive affect of moderate doses of UVB is that in induces the production of vitamin $\mathrm{D}$ and vitamin $\mathrm{K}$.

\section{(c) Biological Effects of UV-C Exposure to Skin}

- The most common injuries of UVC are corneal burns and erythema or severe skin burns.

- $\quad$ UVC burns are painful, but most injuries are short lived.

- Excessive exposure to UVC causes skin cancers as UVA and UVB [19].

\subsection{Health Effects on Humans' eye}

\subsubsection{The Eye}

Light passes through the cornea, pupil and lens onto the retina. It is then converted to nerve impulses which are transmitted to the brain where the sensation of sight takes place. The protective mechanisms of the eye, constriction of the pupil and closure of the eyelids, are activated by bright visible light, not by UV. There are no beneficial ocular effects of exposure to UV.

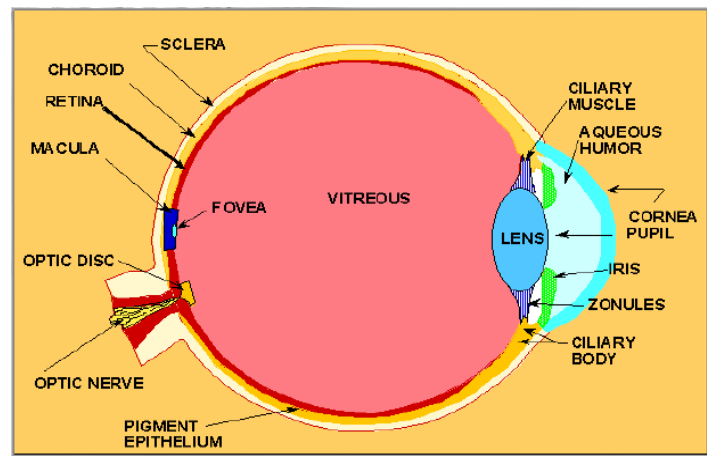

Figure 4: Humans' Eye [19]

\subsubsection{Health Effects on The eye}

In addition, UV light has a profound effect on the eyes. Every year, approximately, 3millionpeoplelosetheirsight because of UV-related damage such as cataracts, which underlines the need to incorporate photo protective measures for the care of the eyes [20].

\section{(a) Effects on The Cornea}

Photo keratitis is the primary acute effect of exposure to intense UV from the sun or welding arcs. This leads to damage to the outer layers of the cornea, causing severe pain and reduced vision, resulting from a corneal haze which develops from the injury and forcing closure of the eyelids. Photokeratitis results from sunlight exposure only in highly reflective environments, such as snow, hence the term "snow-blindness". Photo keratitis is caused by artificial light sources only when there is a substantial UV component, such as from arc welding (where it is frequently referred to 


\section{International Journal of Science and Research (IJSR) \\ ISSN (Online): 2319-7064}

Index Copernicus Value (2013): 6.14 | Impact Factor (2014): 5.611

as "welders' flash" or "arc eye"). Like sunburn, photo keratitis appears a few hours after exposure and is reversible. Symptoms generally disappear within a day or two.

Pterygium is a vascular growth on the surface of the eye and is a common cosmetic blemish with a tendency to become inflamed. When pterygium extends over the centre of the cornea it reduces vision. It is amenable to surgery but tends to recur. Pterygium is likely to be caused, at least in part, by prolonged exposure to UV.

Climatic droplet keratopathy is a blinding degeneration of the cornea that occurs in areas of the world characterized by a harsh climate. In these regions climatic droplet keratopathy is a major cause of blindness which is intimately associated with exposure of the eye to UV.

Diseases of the retina among adults, only small amounts (1\% or less) of UV reach the retina because of absorption by the cornea and lens. However, because UV is known to damage tissue, the importance of this small amount as a cause of retinal damage cannot be ignored. It has been suggested that age-related macular degeneration (a loss of central reading vision) is associated with light exposure. This disease is a common cause of untreatable blindness in the developed world.

\section{(b) Cancer of the Eye}

Malignant melanoma is the most common malignant cancer of the eyeball and occasionally necessitates its surgical removal. A common location for basal cell carcinoma is on the eyelids. There is evidence indicating that these cancers are associated with lifelong exposure to the sun.

\section{(c) Effects on the Lens}

Cataract is the leading cause of blindness in the world. It is a loss of transparency of the lens of the eye. Cataract appears to different degrees in most individuals as they age. It is amenable to surgical removal, and with insertion of an intraocular lens or other means of optical correction, vision can be restored. It is widely accepted that lifelong exposure to UV is associated with the formation of certain types of cataract [15].

\subsubsection{Eye Damage Wavelengths}

UV-A: 315-400 nm UV-B: 285-315 nm UV-C: 100-285 nm Natural UV- C absorbed by air. No penetration. Commercial UV-C hits the Cornea, UV-B hits Cornea, UV-A hits lens

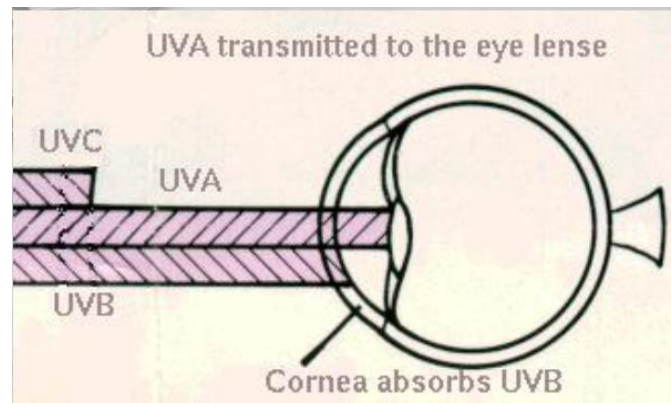

Figure 5: Eye Damage Wavelengths Simplified Cartoon [19] (a) Biological Effects of UV-A Exposure to Eyes

- UV-A passes through the cornea to the lens and overexposure contributes to the formation of cataracts by creating oxidants that cause accelerated formation of cataracts.

- Corneal damage is possible since UVA passes through it to get to the lens.

- A cataract is any opacity or loss of transparency of the lens of the eye. Blurry vision and eventual blindness occur.

\section{(b) Biological Effects of UV-B Exposure to Eyes}

- Photo keratitis, Welders Flash, or Arc Eye is literally burning of the cornea by intense exposure to UVB. It is a painful inflammation that leaves lesions on the cornea.

- Cataracts can form as described with UVA affects.

- Inflammatory, invasive and proliferating lesions called pterygia can form on the cornea.

- Pinguecula or yellowish deposits between the cornea and sclera can occur.

\section{(c) Biological Effects of UV-C Exposure to Eyes}

- Although literature on UVC damage is scarce since it is relatively benign in the natural form, it is the most dangerous form industrially. It can cause damage to eyes in as little as 3 seconds and DNA damage to all biological surfaces.

- Photokeratitis is prevalent documented injury.

- Chronic exposures to acute intense UVC can lead to cataract formation and retinal damage [19].

\subsection{Sources of UV radiations in medical field (Photo- therapy Lamps)}

Artificial sources of UVB in phototherapy lamps are used primarily for clinical purposes.

Acne, psoriasis, neonatal high levels of bilirubin, and daylight deprivation depression are some of the ailments treated with UVB. The exposures times and radiation intensities are controlled and should not cause any unusual harmful effects that one would not get in sunlight. Regardless, equipment should be monitored regularly to avoid accidental overexposure [19].

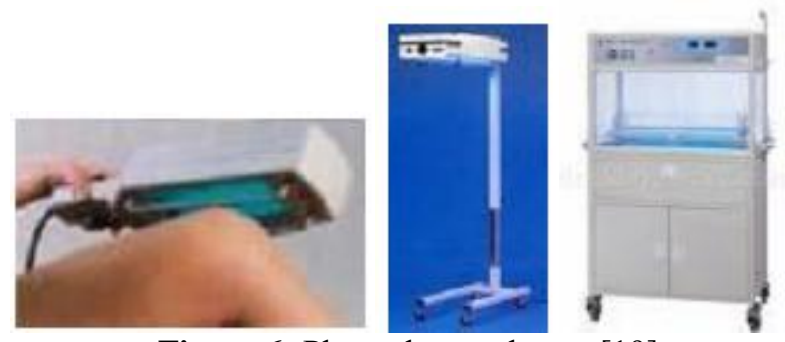

Figure 6: Photo-therapy lamps [19]

\subsection{Need of textile in medical field}

7.4.1 Clothes for people with sensitive skin Peoples who have a sensitive skin need clothes with special UPF rating as follows: 


\section{International Journal of Science and Research (IJSR) \\ ISSN (Online): 2319-7064}

Index Copernicus Value (2013): 6.14 | Impact Factor (2014): 5.611

Table 3: Correspondence between solar rays and the universal UV index and recommendations for UVR protection [21]

\begin{tabular}{|c|c|c|c|c|}
\hline UV in dex 1-2 & UV index $3-4$ & UV in dex 5-6 & UV in dex $7 \cdot 8$ & $\begin{array}{l}\text { UV index } 9 \\
\text { and above }\end{array}$ \\
\hline \multicolumn{5}{|c|}{$\frac{\text { duration of exposure to the sun without protection }}{\text { for sensitive skin/ for normal skin }}$} \\
\hline $\begin{array}{l}\text { weak sun } \\
\text { continuous } \\
\text { exposure of } \\
1-2^{\mathrm{h}} / 3^{\mathrm{h}}+\end{array}$ & $\begin{array}{l}\text { moderate sun } \\
\text { continuous } \\
\text { exposure of } \\
40^{\mathrm{min}} / 1^{\mathrm{h}} 30^{\mathrm{min}}\end{array}$ & $\begin{array}{l}\text { strong sun } \\
\text { continuous } \\
\text { exposure of } \\
25^{\min } / 50^{\min }\end{array}$ & $\begin{array}{l}\text { very strong sun } \\
\text { continuous } \\
\text { exposure of } \\
20^{\mathrm{min}} / 40^{\min }\end{array}$ & $\begin{array}{c}\text { extremely strong } \\
\text { sun } \\
\text { continuous } \\
\text { exposure of } \\
15^{\min } / 30^{\min }\end{array}$ \\
\hline \multicolumn{5}{|c|}{$\frac{\text { recommendations for UVR personal and environmental protection }}{\text { for sensitive skin/ for normal skin }}$} \\
\hline sun glasses & $\begin{array}{l}\text { sun glasses + } \\
\text { sunscreen } \\
\text { with SPF } 15 \\
\text { / sun glasses }\end{array}$ & $\begin{array}{l}\text { sun glasses + hat + } \\
\text { T-shirt + } \\
\text { sunscreen with } \\
\text { SPF } 25+\text { sunshade } \\
\text { / sun glasses + hat } \\
+ \text { sunscreen with } \\
\text { SPF } 15\end{array}$ & $\begin{array}{c}\text { sun glasses + hat + } \\
\text { T-shirt + sunscreen } \\
\text { with SPF } 40+ \\
\text { sunshade / sun } \\
\text { glasses + hat + } \\
\text { sunscreen with SPF } \\
30\end{array}$ & $\begin{array}{c}\text { exposure strongly } \\
\text { discouraged / sun } \\
\text { glasses + hat + } \\
\text { sunscreen with SPF } \\
40+\text { sunshade }\end{array}$ \\
\hline
\end{tabular}

\subsubsection{Eye patches for patients who need a medical} therapy

The appropriateness and selection of protective eyewear are dependent on the:

- Intensity and spectral emission characteristics of the UV source.

- Behavioral pattern of people near UV sources (distance from the source and time near the source are important factors for reducing UV exposure).

- The attenuation of UV provided by the eyewear.

- Design of the eyewear frame to prevent exposure to direct UV [15].

\section{Textiles as protection from ultraviolet radiation}

A part from drastically reducing exposure to the sun, the most frequently recommended form of UV protection is the use of sunscreens, hats, and proper selection of clothing. Because fabric is composed of fibers that can absorb, reflect or scatter radiant energy, it has the ability to absorb and/or block most of the incident radiant energy and prevent it from reaching the skin. Fig (I.2) is a schematic representation of the different ways a fabric can prevent UV radiation from coming into contact with the skin. However, a fabric's ability to block UVR is dependent on several parameters [22], [23], [24].

The construction of woven and knitted fabrics and the fiber types have a great influence on protection from ultraviolet transmittance. The ultraviolet protection factor (UPF) of textiles depends on their construction, the spaces between the yarns, their fiber types, the color, the textile impregnation, and the presence of optical brighteners and ultraviolet absorbers [4].UPF also can be affected with wearing conditions or it can be improved by incorporating Tio2 into its structure [25].
Figure 7: Schematic representation of a textile as a barrier to UV radiation [23]

\subsection{Parameters affecting UV protection of textile}

\subsubsection{Parameters related to fabric specifications \\ (a) Material and Composition}

Different fabrics absorb UV radiation at different levels. Most cotton or cotton/polyester blend fabrics provide protection equal to about UPF 20 (which is about $95 \%$ protection from UV radiation). Fabrics offer less protection when wet.

Summer clothing is usually made of cotton, viscose, rayon, linen, polyester, or combinations thereof. Other types of materials, such as nylon or elastane, are also found in bathing suits, nylon stockings, and other garments.

Consumers generally consider lightweight non-synthetic fabrics (cotton and linen) to be the most comfortable for summer wear. Comparison of the UPF of different types of material is difficult and possible only in limited situations.

This is because certain production steps (dyeing and finishing) vary based on the material, resulting in a comparison of the -ranterial-color-finish" combination and not of the material itself. In the case of Synthetic fibers, such as polyester and polyamide, an analysis is even more difficult because the UV protection of these materials depends on the type and quantity of additives to the fiber, such as antioxidants or UV stabilizers. In accordance with most studies, the type of fiber used to construct a textile can have a substantial effect on the UPF, especially for white and non-dyed fabrics [13]. Bleached cotton and viscose rayon are transparent to UV radiation and thus provide relatively low UV protection [26]. This was recently confirmed by Crews et al, who reported that bleached cotton print cloth had a UV transmission of $23.7 \%$, whereas the same unbleached fabric had a UV transmission of only $14.4 \%$. The effect of bleaching was also evident among silk fabrics in their study. Compared with bleached textiles, unbleached fabrics such as cotton and silk have better UV protective properties due to UV-absorbing natural pigments and other impurities. Polyester usually has good UV blocking properties, as this fabric allows relatively little UV-B transmission, probably because of the large conjugated system of polymer chains. Polyester (or polyester blends) may be the most suitable fabric type for UV protective garments. However, its permeability for wavelengths in the UV-A range is frequently higher than that of other fiber types; this could be of significance for wearers with polymorphic light eruption, solar urticaria, chronic actinic dermatitis, or actinic prurigo.

\section{Volume 4 Issue 12, December 2015}




\section{International Journal of Science and Research (IJSR) \\ ISSN (Online): 2319-7064 \\ Index Copernicus Value (2013): 6.14 | Impact Factor (2014): 5.611}

\section{(b) Fabric Constructions}

A part of the radiation is reflected at the boundaries of the textile surface. The UVR transmitted through textile fabrics consists of the unchanged waves that pass through the interstices of the fabrics as well as scattered waves that have interacted with the fabrics. Another part is absorbed when it penetrates the sample, and is converted into a different energy form. The portion of radiation that travels through the fabric and reaches the skin is appropriately referred to as the „transmission component.

To achieve a minimum UPF rating of 15 , the cover factor of the textile must be greater than $93 \%$, and a very small increase in CF leads to substantial improvements in the UPF of the textiles above $95 \%$ cover factor. In the case of terry cloth, a high variability in UPF exists due to irregularities in the fabric construction. Woven fabrics usually have a higher cover factor than knits due to the type of construction. Thick rib structures of hemp and linen can allow $10.52-12.70 \%$ and $9.03-11.47 \%$ of UV A and UV B respectively. However, knitted structure made from a blend of synthetic fibers with Lycra offers the best protection against solar radiation, and warp-knitted blinds are capable of screening up to $80 \%$ of the solar radiation and bright glares [9].

\section{(c) Porosity, Weight, Thickness, and Fabric density}

The closer the fabrics' weave, the higher the UV radiation protection, because the fibers of tightly woven fabrics are closer together, less UV radiation is able to pass through to the skin. Tightly woven, light weight fabrics such as linen, cotton or hemp will also help keep you cool. Repeated washing can improve the UPF of clothes, especially cotton, by shrinking gaps in the weave. However, old, threadbare or faded clothes may have a lower UPF rating.

Researchers have referred to fabric porosity by a variety of terms, including cover factor, tightness of weave, and fabric openness. Cover factor may be defined as the percentage area occupied by warp and filling yarns in a given fabric area. To understand the relationship between UV transmission and fabric structure, an ideal" fabric is proposed, in which the yarns are completely opaque to UV radiation and the holes or spaces between the yarns are very small. From the literature it is known that UPF depends on fabric weight as well as on fabric thickness [13],[ 27] Ultraviolet transmission through ideal fabric is related to the cover factor of the fabric with opaque yarns as follows: $\%$ UV transmission=100/(100-cover factor).\% $[13,26]$

A fabric construction is the primary determinant of fabric porosity, followed by fabric weight. The closer the weave or knitting, the less UV radiation is transmitted. Spaces between the yarns are generally larger in a knit fabric than in a woven textile, and plain woven textiles have a lower porosity than textiles woven using other weaves. An increase in weight per unit area also decreases fabric porosity. The spaces between the yarns are smaller in heavier textiles, permitting transmission of less UV radiation. However, yarns are usually not opaque to UV radiation; thus, UPFs of actual fabrics are lower than those of an ideal fabric. In most studies, thickness measurements for the fabrics were not undertaken or reported. However, thickness is a useful variable for understanding differences in UV protection between fabrics. Crews and coworkers reported that thicker, denser fabrics transmit less UV radiation and concluded that thickness is most useful in explaining differences in UV transmission when differences in percentage cover factor are also accounted for [13].

\section{(d) Production Techniques}

The cover factor can be modified through many dry finishing processes through overfeed on the stenter, compressive shrinkage processes such as compacting and sanforising, which are normally used to obtain dimensional stability, incidentally increasing the cover factor and hence the UPF. A protective effect can be obtained by dyeing or printing, which is better than using heavyweight fabrics which are not suitable for summer conditions [9]

\section{(e) Dyeing and Treatment}

Many dyes absorb UV radiation. Darker colors (black, navy, dark red) of the same fabric type will absorb UV radiation more than light pastel shades (white, sky blue, light green). They will therefore have a higher UPF rating. Also some clothing is treated so it can absorb more UV radiation. Check the clothing label to see if your clothes have been treated [28].

The dyes used to color a textile can affect the UV protectiveness of a fabric, depending on the position and intensity of the UV wavelength absorption bands of the dyes and the concentration of the dyes in the textile. The absorbance of UV radiation can affect substrate attributes, including fluorescence, photo degradation, and UV protection. Generally, dark colors provide better UV protection due to increased UV absorption. However, particular hue dyes can vary considerably in the degree of UV protectiveness because of individual transmission and absorption characteristics. To improve UV protection, UV absorbers have been added using different techniques. Ultraviolet absorbers for laundry detergents and rinse cycle application have been recently developed. Ultraviolet absorbers are colorless compounds that absorb in the wavelength range of 290 to $400 \mathrm{~nm}$. Hilfiker and colleagues found that cover factor was useful in predicting the maximum UPF achievable by treating yarns with UV absorbers. Thus, fabrics could be made opaque to UV radiation with a sufficient level of UV absorber impregnation, and the corresponding UPFs approached the theoretically predicted levels based on the cover factor. Titan dioxide of various particle sizes is frequently used as a UV absorbing substance in fabrics; however, the absorption of these particles is frequently less protective in the UV-A wavelength range. Other manufactured UV absorbers also provide less protection from UV-A radiation, which should be considered when counseling patients with photosensitivity disorders. However, UV absorbers are suitable for enhancing UV protectiveness especially that of non-dyed lightweight summer fabrics, such as cotton and viscose, which offer a high level of wearing, comfort [13], [ 29].

\section{(f) Design}

Choose clothing that covers as much skin as possible. Collared shirts and at least three-quarter length trousers and three-quarter length sleeve tops cover skin well. A shirt with long sleeves and a large collar offers much better protection

\section{Volume 4 Issue 12, December 2015}




\section{International Journal of Science and Research (IJSR) \\ ISSN (Online): 2319-7064 \\ Index Copernicus Value (2013): 6.14 | Impact Factor (2014): 5.611}

than clothing such as singlet tops. Loose-fitting clothes give better protection than closefitting clothes and may be more comfortable to wear on hot days. Darker colors generally offer more protection than lighter colors [12], [13].

\subsubsection{Wearing Conditions Affecting UV protection of textiles}

\section{(a) Stretch}

Stretching a textile causes an increase in fabric porosity, with a consequent decrease in UPF. Moon and Pailthorpe found that stretching elastane-based garments about $10 \%$ in the machine and cross-machine directions causes a dramatic decrease in the measured UPF of a textile. Their consumer survey also showed that, on average, about $15 \%$ stretch is achieved when these textiles are worn. However, the $15 \%$ is for power-stretch" garments, which are only a small segment of the clothing market and elastane-based textiles for tight fitting clothes should not be considered as UV protective clothing. Kimlin et al reported that the UPF of 50denier stockings decreased $868 \%$ when stretched $30 \%$ greater than their original size. Notably, the most popular type of stockings (15-denier) provides a UPF of less than 2. The maximum stretch point on the body for tight fitting garments is the upper back, where textiles can be stretched up to $15 \%$. However, realistically, the effect of stretch on the UPF of a textile may be significant only for garments with a non-stretched UPF of less than 30, particularly leggings, women's stockings, and swimsuits [13], [26].

\section{(b) Wetness}

When textiles become wet, by air hydration, perspiration, or water, UV transmission through the fabric can significantly change, with a marked reduction of UPF observed for textiles made from cotton and cotton blends. In a field-based study, it was recently shown that significant UV exposures may occur beneath garments, particularly those made of white cotton fabrics when wet. Moreover, wetting of stretched polyamide and elastane fabrics causes a large reduction in measured UPF. Similar results were also found for in vivo measurements of UPFs of cotton and polyester blends. One explanation for this is that the presence of water in the interstices of a fabric reduces optical scattering effects and, hence, increases UV transmission of the textile. This is analogous to a T-shirt that becomes transparent when wet. However, UV protection of wet garments is not necessarily poor. In fabrics made of viscose or silk, or in fabrics that have been treated with broadband UV absorbers, the UPF may increase when the textile becomes wet. This was also observed in a recent study of modal and polyester crepe fabrics treated with titan dioxide [13], [30].

\section{(c) Laundering}

Stanford and coworkers conducted laundering trials using cotton T-shirts. They showed that UPFs increased after the first washing and did not change significantly with subsequent washing. The original UPF of a new cotton Tshirt was found to be 15 , increasing to UPF 35 after the first laundering. These UPFs were obtained when participants were instructed to wear their T-shirt for 4 to 8 hours per week and to wash their T-shirt once per week for 10 wash and wear cycles. Most fabrics undergo a combination of relaxation and consolidation shrinkage when washed. Thus, the spaces between the yarns decrease and UV protection increases. The effect of laundering on UPF raises questions about qualities and factors of other fabrics that decrease UPF. However, there is a lack of reports of wash-and-wear trials using other fabric types [13].

\section{Conclusion}

The ultraviolet radiation consists of three regions: UV-A (320 to $400 \mathrm{~nm}$ ), UV-B (290 to $320 \mathrm{~nm}$ ), and UV-C (200 to $290 \mathrm{~nm}$ ). UV-C can't reach the earth because the atmosphere absorbs it. UV-A has a little effect on the skin but it affects the skin cells. UV-B causes skin cancers. ( squamous cell, basal cell carcinoma, melanoma) which can cause death. UV radiations also has a very dangerous effects on eye ,as it can cause blindness or eye cancer .So everyone must avoid it or use protective ways.

Some of protective ways from UV are using sunscreens, hats. Also clothes protect skin from UV radiations because clothes' fabrics contain fibers which absorb, reflect or scatter radiations. Fabrics can be tested to determine its' ultraviolet protection in vivo to determine its' sun protection factor (SPF) or in vitro using measurement instrument tested to determine its' ultraviolet protection factor (UPF). Some parameters can affect fabric's UPF like (Material, fabric construction, porosity, thickness, weight, Dyeing and finishing). Also wearing conditions (stretching, laundering and wetness).

\section{References}

[1] Julian M. Menter, Kathryn L. Hatch —Cdthing as Solar Radiation Protection" Textiles and the Skin. Curr Probl Dermatol. Basel, Karger, Vol. 31, 2003, page 50-63.

[2] S.Ghazi,C.Couteau,L.J.M.Coiffard What level of protection can be obtained using sun protective clothing? hDetermining effectiveness using an invitro method" International Journal of Pharmaceutics ,Vol.397, 2010,page 144-146.

[3] Arshia Hussain , Shahnaz Jahan Textiles protection against ultraviolet radiation" The Indian textile Journal , June 2010.

[4] Marija Gorensek and Franci Sluga Modifying the UV Blocking Effect of Polyester Fabric", Textile Research Journal, Vol.74 (6), 2004, Page 469-474.

[5] Eckhardt, C., and Rohwer, H.'UV Protector for Cotton Fabrics", Textile Chem. Color. Am. Dyest. Rep. 32 (4), 2000, Page 21-23.

[6] L. Hunter Ultraviolet protection of fabrics and garments" Wood head publishing in textiles, Engineering apparel fabrics and garments, Page 309334

[7] W. Czajkowski , Joanna Paluszkiewicz , Roland Stolarski ,MariolaKaz'mierska, Edyta Grzesiak Synthesis of reactive UV absorbers, derivatives of monochlorotriazine ,for improvement in protecting properties of cellulose fabrics" Dyes and Pigments Journal ,Vol. 71,2006, Page 224-230.

[8] James R.Liffering - Phototrauma prevention" Wilderness and Environmental Medicine, 12,2001, Page 195-200.

\section{Volume 4 Issue 12, December 2015}




\section{International Journal of Science and Research (IJSR) \\ ISSN (Online): 2319-7064}

Index Copernicus Value (2013): 6.14 | Impact Factor (2014): 5.611

[9] D. Saravanan UV PROTECTION TEXTILE MATERIALS", AUTEX Research Journal, Vol. 7, No 1, March 2007, Page 53-62.

[10] DermNet NZ Sun protective clothing" Created 2006. Last updated 15 Dec 2007. (C) 2008NZDS.http://www.dermnetnz.org/treatments/sunprotective-clothing.html

[11] Inés Algaba, Ascension Riva and Montserrat Pepio Modelization of the Influence of the Wearing Conditions of the Garments on the Ultraviolet Protection Factor", Textile Research Journal ,Vol. 77(11),.2007, Page 826-836

[12] Australian Radiation Protection \& Nuclear Safety Agency (ARPANSA), Resource Guide for UV Products. Yallambie ARPANSA 2003.

[13] Klaus Hoffmann Đefined UV protection by apparel textile", ARCH DERMATOL, Vol. 137, Aug 2001, Page 1089-1094.

[14] Richard F. Edlich, MD, PhD, ${ }^{1 *}$ Mary Jude Cox, MD, ${ }^{2}$ Daniel G. Becker,Jed H. Horowitz, Larry S. Nichter, , L.D. Britt, Theodore J. Edlich III and William B. Long -Reolutionary Advances in Sun-Protective Clothing-An Essential Step in Eliminating Skin Cancer in our World", Journal of Long-Term Effects of Medical Implants,Vol. 14(2),.2009, Page 95-105

[15] M Belkin, et al Protection Against Exposure to Ultraviolet Radiation", World Health Organization, United Nations Environment Programme, August 1994.

[http://www.who.int/uv/publications/proUVrad.pdf]

[16] UV Standard 801 [www.uvstandard801.ch]

[17] Elliot J. Coups, Sharon L. Manne, Carolyn J. Heckman Multiple Skin Cancer Risk Behaviors in the U.S. Population" American Journal of Preventive Medicine, Vol. 34(2), Feb. 2008, Page 87-93.

[18] Torres Woolley, Petra G. Buettner and John Lowe Predictors of sun protection in northern Australian men with a history of nonmelanoma skin cancer" Preventive Medicine Journal ,Vol. 39,2004 , Page 300-307.

[19]

[https://www.case.edu/does/Training/UV/UVsafety.pdf †]

[20] Salvador Gonzalez, Manuel Fernandez-Lorente, Yolanda Gilaberte-Calzada -The latest on skin photo protection",Clinics in Dermatology Journal, 26, 2008, Page 614-626.

[21] Cesarini, J.P"Impact of Ultraviolet radiation on Humans", Indoor and BuiltEnvironment, Vol.10, No.5, 2001,Page 310-316

[22] Capjack, L., Kerr ,N., Davis, S., Fedosejevs, R., Hatch, K.L. and N.L. Protection of humans from ultraviolet radiation through the use of textiles: A Review.", Family and Consumer Science Research Journal, Vol.23(2), 1994, Page 198-218

[23] A.K.SARKAR - Fextile for UV Protection" Wood head publishing in textiles, Textile for protection, Page 355377

[24] Snezana B. Stankovic, Dusan Popovic, Goran B. Poparic and Mateja Bizjak Ultraviolet Protection Factor of Gray-state Plain Cotton Knitted Fabrics", Textile Research Journal ,Vol. 79(11),.2009 , Page 1034-1042
[25] Roshan Paul, Lorenzo Bautista, Meritxell De la Varga, Jose Maria Botet, Eudald Casals, Victor Puntes and Feliu Marsa Nano-cotton Fabrics with High Ultraviolet Protection", Textile Research Journal ,Vol. 80(5),.2010, Page 454-462

[26] Mike Pailthorpe - Aparel textiles and sun protection: a marketing opportunity or a quality control nightmare?" Mutation Research Journal, 422, 1998, Page 175-183.

[27] Polona Dobnik Dubrovski and Darko Golob Effects of Woven Fabric Construction and Color on Ultraviolet Protection", Textile Research Journal ,Vol. 79(4),.2009 , Page 351-359

[28] Gwendolyn Hustyedt and Patricia Cox Crews - The Ultraviolet Protection Factor of Naturalally-pigmented Cotton" The Journal of cotton Science ,Vol. 9,2005 , Page 47-55

[29] Cheryl A. Wilson, Nicola K. Bevin, Raechel M. Laing and Brian E. Nive Solar Protection Effect of Selected Fabric and Use Characteristics on Ultraviolet Transmission", Textile Research Journal ,Vol. 78(2),.2008, Page 95-104

[30] C. A. Wilson and A. V. Parisi - Sunulated Wear and Laboratory Testing-Protection from Solar Erythemal Ultraviolet Radiation", Textile Research Journal ,Vol. 76(3),.2006, Page 216-225 